\title{
A UNIÃO DE NAÇÕES SUL-AMERICANAS: INSTITUCIONALIDADE E DESAFIOS
}

\author{
THE UNION OF SOUTH AMERICAN NATIONS: \\ INSTITUTIONALITY AND CHALLENGES
}

\author{
Alexandre Ganan de Brites Figueiredo ${ }^{(*)}$ \\ Universidade de São Paulo, São Paulo (SP), Brasil
}

Resumo: Este trabalho apresenta a União de Nações Sul-Americanas (Unasul), organização internacional fundada em 2008 que, na visão de diferentes pesquisadores, representa uma nova concepção de integração regional. Se, até então, o foco esteve na integração econômica, a Unasul inova ao trazer objetivos políticos, sociais e culturais, dentre outros, constituindo um projeto mais ambicioso de integração. A partir da análise de conceitos do direito da integração, o artigo discute se as instituições formuladas nos marcos dessa organização são aptas para a realização de seus objetivos.

Palavras-chave: Unasul; Integração Regional; Direito da Integração; América do Sul.

Abstract: This paper presents the Union of South American Nations (Unasul), international organization founded in 2008, and that for many researches is a new conception of regional integration. Until then, he focus was on economic integration, Unasul innovates to bring political, social and cultural objectives, among others, constituting a more ambitious integration project. From the analysis of concepts of integration law, the article discusses whether institutions formulated within the framework of this organization are able to carry their goals.

Keywords: Unasul; Regional Integration; Integration Law; South America.

(*) Mestre, aluno do curso de doutoramento do Programa Interunidades em Integração da América Latina da Universidade de São Paulo (PROLAM/USP); aluno do curso de graduação em Direito da Faculdade de Direito da Universidade de São Paulo (FD/USP).E-mail: <figueiredousp@yahoo.com.br>. Recebido em: 12.12.2013, aceito em: 01.06.2014. 


\section{INTRODUÇÃO}

O objetivo deste trabalho é apresentar a União de Nações Sul-Americanas (UNASUL), discutindo sua originalidade e sua capacidade, a partir de uma perspectiva jurídico-institucional, para cumprir seus objetivos. Nessa perspectiva, entenderemos a Unasul como um "esquema de integração regional", conforme a classificação proposta por Sandra C. Negro ${ }^{(1)}$, ou seja, nos concentraremos nos aspectos propriamente jurídicos dessa organização, bem como em suas instituições. Portanto, considerações de cunho econômico, político ou geopolítico, igualmente relevantes para a abordagem do tema, serão utilizadas como uma perspectiva complementar. Como lembra Umberto Celli Junior, "o conceito de integração sempre foi dinâmico e relacionado a um determinado contexto, político, econômico e social” (CELLI JUNIOR, 2006, p. 19). Por conta dessa natureza, aproximar-se desse objeto de estudo é uma tarefa que exige do pesquisador uma abordagem necessariamente interdisciplinar e a partir de vários vértices, ainda que seu foco esteja apenas em um. Dessa forma, priorizamos a abordagem histórica e jurídica sem desconsiderar as demais em sua igual importância para a compreensão do fenômeno.

A partir desse marco (o direito da integração), dessa perspectiva (análise do esquema de integração regional) e dessas fontes jurídicas (os instrumentos normativos desta organização, especialmente seu Tratado Constitutivo), procuraremos discutir a capacidade da Unasul em responder aos seus ambiciosos objetivos. Com a análise de suas instituições e, especialmente, de seu caráter intergovernamental, bem como da derrotada defesa da supranacionalidade, discutiremos como a Unasul lida com os as contradições inerentes ao processo de integração e à história da região.

O Tratado Constitutivo da organização acaba reproduzindo essas contradições e, por isso, realçamos que não se trata de atecnias, mas da própria realidade sub-regional. Um exemplo é o fato de a Unasul ser formada tanto por países claramente orientados para a opção por acordos preferenciais de comércio e, portanto, impedidos de compor uma união aduaneira, mercado comum ou união econômica sub-regional, como por países cuja política externa é marcada pelo confronto com a liberalização. Chile, no primeiro caso, e Venezuela, no segundo, são exemplos. Além disso, a UNASUL precisa conciliar no seu interior o Mercosul, a Comunidade Andina e a Aliança Bolivariana para as Américas (ALBA-TCP).

Se incluirmos ainda as contradições econômicas internas, como a profunda assimetria entre os Estados da Unasul terá um cenário contraditório que, inevitavelmente, leva a institutos jurídicos que tenham que lidar com a contradição. É por si só notável o fato de os 12 estados sul-americanos terem, de forma inédita, acertado os termos de um acordo com pontos comuns para a região como um todo. É razoável pensar que mesmo com tamanhas diferenças há, nos últimos anos, uma vontade política mais forte pró-integração do que contrária. O que nos interessa na análise dos aspectos jurídicos

(1) Sandra C. Negro (SD) apresenta três aspectos para a abordagem da integração regional. Além da jurídico-institucional ("esquemas de integração"), há a histórico-política ("processo de integração") e ainda a econômica e comercial ("bloco econômico regional"). NEGRO, S. C. "Caracterización y classificación de los esquemas de integración regional". In: NEGRO S. C (dir.). Derecho de la Integración - Manual. Montevideo/Buenos Aires: Editorial IB de F. 
da integração é se, nesse processo, e essa vontade política foi de fato institucionalizada a contento. Para balizar a apresentação do debate teórico, nos valemos em especial das contribuições de diversos especialistas publicadas no anuário da Coordinadora Regional de Investigaciones Económicas y Sociales (CRIES).

\section{A UNASUL ENQUANTO NOVIDADE TEÓRICA}

Existe um relativo consenso entre os estudiosos da integração latino-americana quanto a se considerar a Unasul uma novidade teórica. Assim, afirmam vários autores que veem essa organização como uma resposta da América do Sul ao predomínio antes exercido pelos parâmetros do Consenso de Washington e do chamado "novo regionalismo". O elemento novo trazido seria o fato de os objetivos da Unasul irem além da integração comercial e econômica, abrangendo os âmbitos político, cultural, social e ambiental. Sabemos que esse último fato por si só não é exatamente novo. Como lembra Umberto Celli Junior, embora possam existir blocos regionais a partir de diversos vetores, inclusive afinidades culturais ou mesmo religiosas, são os fins econômicos que predominam (CELLI JUNIOR, 2006, p. 20). Sendo assim, se no âmbito da teoria das organizações regionais de integração não é uma completa novidade o caráter extraeconômico da Unasul, é certamente nova sua opção quando consideramos o predomínio dos temas econômicos e as demais iniciativas de integração da região.

José Antonio Sanahuja discute essa questão. Ele lembra que desde 1990 predominou na América Latina o Regionalismo Aberto. Diversas estratégias foram adotadas pelos estados, mas todas orientadas por essa vertente liberal da integração: México se integrou aos EUA com o NAFTA, o Chile se distanciou dos vizinhos optando por estabelecer tratados bilaterais de livre-comércio, o grupo de países andinos converteu-se em Comunidade Andina, adotando princípios do Regionalismo Aberto. Mas, na primeira década do século XXI, teria surgido um “regionalismo pós-liberal”, do qual a Unasul é uma expressão. Caracterizam a novidade da Unasul e desse regionalismo pós-liberal, na visão de Sanahuja, os retornos da agenda política a um âmbito até então dominado pela agenda comercial, de um projeto de desenvolvimento atrelado à integração e da busca por autonomia tanto perante os mercados como diante dos Estados Unidos (autonomia que Sanahuja chama de "meta explícita do regionalismo pós-liberal"). (SANAHUJA, 2012, p. 32).

Como consequência, vem à cena a preocupação com a falta de infraestrutura voltada para a integração, como ligações físicas entre os estados, a atenção à existência de assimetrias regionais que devem ser reduzidas para garantir a viabilidade do processo de integração e, por fim, a afirmação do compromisso com a participação da sociedade civil. Além disso, também há novidade na ênfase dada a uma "agenda positiva da integração", como a introdução de temas como a cidadania, os direitos humanos, a redução da pobreza, a cultura e o meio ambiente. Tais temas dão à Unasul um discurso ideológico e fazem com que a integração seja vista como instrumento de desenvolvimento e de justiça social. Sanahuja chega a considerar inadequado avaliar a Unasul dentro do marco da integração econômica, sendo melhor defini-la como uma "organização de cooperação política" (SANAHUJA, 2012, p. 32). 
Pía Riggirozzi (RIGGIROZZI, 2012, p. 144) acentua a novidade da Unasul nos objetivos mais amplos que ela traz quando comparada aos objetivos dos marcos do Regionalismo Aberto. Em suas palavras, a Unasul:

"Es fundamentalmente una construcción regional que capitaliza sobre acuerdos de 'regionalismo abierto' de la década de 1990, pero que se construye sobre un objetivo nuevo: fortalecer una estructura institucional en temas más allá del comercio, mientras se busca, al mismo tempo una posición autónoma en relación al frente externo, y espacialmente en relación a actores como EE.UU o la EU."

Na sua avaliação, Riggirozzi considera que a ascensão desse novo objetivo se deve a uma mudança no cenário político sul-americano, com a chegada ao poder de grupos de esquerda de diferentes matrizes, mas concordes na crítica ao Consenso de Washington e ao "neoliberalismo". Essa mudança teria se expressado também em novas práticas e construções institucionais regionais. Dentre os novos modelos de integração que surgem nesse contexto haveriam dois projetos, um radical e outro moderado. O primeiro seria a ALBA, defensora de um modelo socialista ou um "welfarismo transnacionalizado", na expressão de Riggirozzi. O segundo modelo seria a Unasul que propõe novos temas e objetivos para a integração sem abrir mão dos velhos objetivos comerciais (em verdade, a Unasul se apoia sobre aqueles eixos comerciais) (RIGGIROZZI, 2012, p. 133).

Outra analista do tema, César Augusto Bermúdez Torres (2011, p. 120) afirma que a Unasul inova quando busca transcender o caráter econômico da integração. Na sua opinião, isso não implica em desmerecimento do papel da integração econômica, até porque "cuando empieza el siglo XXI el Mercado Común del Sur es el proyecto más representativo de la región suramericana por sus antecedentes y por su legado". Contudo, ao tentar ampliar os objetivos iniciais de um organismo de integração, a Unasul representaria uma nova estratégia. Esse autor também concorda que foi determinante para essa nova orientação o fato de a América do Sul ser governada, na maioria de seus países, por partidos de esquerda e centro-esquerda. Mesmo a Colômbia, que não é um desses países, depois da eleição de Juan Manuel Santos, alinhou-se à nova orientação, acolhida pelos demais com a nomeação de sua chanceler, Maria Emma Mejía, para a Secretaria Geral da Unasul.

O geopolítico Miguel Ángel Barrios (2011) acredita que a Unasul é parte de um processo de "latinoamericanização", ou seja, da retomada do projeto integracionista do século XIX. Nisso ela representa um avanço em relação aos organismos de integração sobre os quais ela se erige. Para Barrios, como bom discípulo de Methol Ferré, trata-se de consolidar um grande estado-continental que permita à América do Sul uma inserção soberana no mundo globalizado. A Unasul e, especialmente, seu Conselho de Defesa, inovariam por serem as ferramentas para a consolidação desse projeto secular da região (BARRIOS, 2011).

Félix Peña (2009), especialista em integração latino-americana, vê na Unasul a mais recente tentativa de criar um âmbito institucional para toda a região. Também afirma que a inovação, assim como os demais autores citados acima, advêm de seu objetivo de ir além da mera convergência econômica dos organismos já existentes (a CAN e o Mercosul). 
Elsa Llenderrozas (2012, p. 158) também concorda que a Unasul representa uma novidade. Na sua avaliação, é possível perceber como a Unasul é um personagem novo no palco da integração quando tentamos defini-la e classificá-la: "En cuanto a su naturaleza, Unasur no es facilmente asimilable a ninguno de los conceptos aplicados hasta ahora en los procesos de regionalización, como ser: área de libre comércio, unión aduaneira, mercado común, unión monetária." A novidade estaria, também na opinião de Llanderozas, na construção de uma agenda multidimensional.

Maria Angeles Cano Linares adota a mesma linha: "Se puede afirmar que, con Unasur, se há generado una nueva y peculiar iniciativa en la heterogénea y diversa realidad de integración que acontece en el continente americano desde finales se los años cincuenta del pasado siglo" (LINARES, 2010, p. 11). Essa nova iniciativa veria a integração como um instrumento para assegurar a qualidade de vida dos povos da região.

Miriam Gomes Saraiva (2012, p. 87-100) também enxerga uma mudança no cenário da integração, no qual as iniciativas voltadas para a liberalização estariam perdendo centralidade em prol de novas experiências cuja expressão é a Unasul. A definição que Saraiva dá a essa organização internacional demonstra como é realmente difícil conceituar essa iniciativa peculiar: "la Unasur tiene un perfil diferente de las otras iniciativas y se acerca más a un instrumento de gobernanza regional que a los patrones clássicos de integracion”. Essa autora já vê a Unasul como organismo de integração, como outros autores, evidenciando a dificuldade em se abordar o objeto de pesquisa.

Organismo de integração, de cooperação ou de governança regional? Pelos autores citados acima é possível vislumbrar a dificuldade de se definir a Unasul. O único consenso se dá quanto à existência de uma novidade teórica para a integração regional, além de uma mudança política em relação à orientação que se dava ao tema na região antes das tratativas que culminaram na União de Nações Sul-Americanas.

\section{OBJETIVOS E INSTITUCIONALIDADE DA UNASUL}

Em 23 de maio de 2008, foi assinado, em Brasília, o Tratado Constitutivo da Unasul (TC). Os 12 países que já integravam a CSN (Argentina, Brasil, Uruguai, Paraguai, Chile, Peru, Equador, Colômbia, Venezuela, Guiana e Suriname) foram os signatários. Seguindo a disposição do art. 26, o TC entrou em vigor em 11 de março de 2011, 30 dias depois da comunicação da nona ratificação (feita pelo Uruguai) ao Equador, país encarregado de receber as ratificações. Hoje, todos os estados que assinaram o TC já concluíram o processo de ratificação, formando a primeira organização internacional com todos os países da América do Sul em um contexto no qual se procuram novas perspectivas para a integração.

O processo de formação da organização vem desde o ano 2000 quando, por inciativa do então presidente Fernando Henrique Cardoso (1995-2002), reuniram-se em Brasília todos os presidentes sul-americanos a fim de lançar as bases de um entendimento comum e uma futura organização regional. Depois dessa reunião, outras duas foram realizadas nos anos 2002 e 2004, sendo que dessa última resultou a fundação da Comunidade Sul-Americana de Nações (CSN), organização sem personalidade jurídica 
internacional. Por sua vez, a CSN realizou duas reuniões ordinárias, nos anos de 2005 e 2006. Em uma reunião extraordinária de 2007, realizada para debater o tema energia, a Comunidade alterou seu nome para União de Nações Sul-Americanas.

Já, em 2008, realizou-se a primeira reunião da Unasul na qual foi assinado o Tratado Constitutivo da organização, agora dotada de personalidade jurídica. Neste ano, houve uma mudança nos princípios que orientavam a iniciativa. A primeira década do século XXI viu chegar ao poder grupos políticos que faziam a crítica aos postulados do Consenso de Washington. As eleições de Luiz Inácio Lula (2002), Néstor Kirchner (2003), Tabaré Vázquez (2004), Evo Morales (2005), Rafael Correa (2006) e Fernando Lugo (2008), somando-se à de Hugo Chávez, que já presidia a Venezuela desde 1999, contribuíram para uma alteração na concepção de integração regional. Enquanto o Comunicado de Brasília, emitido como resultado do encontro de 2000, se comprometia com a construção da Área de Livre-Comércio das Américas (ALCA) e tomava cuidado ao afirmar que uma identidade sul-americana não excluiria outras nações do mundo (BRASÍLIA, 2000), a Declaração de Cuzco, documento de 2004 fundador da CSN, já abandonava a perspectiva da ALCA e contemplava demandas de autonomia e desenvolvimento, além de assumir um conteúdo social acentuado, constituindo uma linha que está presente na Unasul.

O TC da Unasul foi aprovado a partir de um projeto formulado pela Comissão de Altos Funcionários, ainda no âmbito da CSN. Um dos membros dessa Comissão, Pablo Sólon, boliviano que também foi o Secretário-Geral Pro Tempore da Unasul no período imediatamente anterior à assinatura do TC, lembra que a integração de doze países deve ser o difícil encontro das vontades políticas desses doze países, com muitas diferenças entre si (SÓLON, 2008, p. 12). Como não poderia deixar de ser, o TC expressa as contradições advindas dessa difícil convergência. Os objetivos da Unasul estão divididos em dois artigos do tratado. $\mathrm{O}$ artigo $2^{\circ}$ traz um objetivo geral, que sintetiza os fins almejados pelas Reuniões de Presidentes e pela CSN:

\footnotetext{
Artigo 2ํㅡ A União de Nações Sul-Americanas tem como objetivo construir, de maneira participativa e consensuada, um espaço de integração e união no âmbito cultural, social, econômico e político entre seus povos, priorizando o diálogo político, as políticas sociais, a educação, a energia, a infra estrutura, o financiamento e o meio ambiente, entre outros, com vistas a eliminar a desigualdade socioeconômica, alcançar a inclusão social e a participação cidadã, fortalecer a democracia e reduzir as assimetrias no marco do fortalecimento da soberania e independência dos Estados. (UNASUL, 2008.)
}

Este artigo já traz os princípios da participação e do consenso, que devem orientar o processo de integração trazido pela Unasul — o artigo 12 dispõe também que todas as decisões serão aprovadas apenas mediante o consenso. A América do Sul seria um espaço integrado cultural, social, econômica e politicamente, cujas finalidades são tão amplas quanto complexas como a eliminação da desigualdade socioeconômica. Para melhor explicitar suas metas, o TC dedicou ao tema também o artigo 3ํ definindo 21 objetivos específicos. Resumidamente, no plano econômico, a Unasul pretende constituir-se em uma zona de livre-comércio sul-americana, apoiando-se na experiência das duas uniões aduaneiras regionais. No plano político, projeta-se como garantia da democracia e como 
um fórum de governança regional, articulando uma posição comum nas relações exteriores e na política de defesa. No plano da integração dos povos a Unasul pretende fomentar a integração cultural e a constituição de uma cidadania sul-americana. $\mathrm{O}$ rol desses objetivos mais precisos não torna a sua dimensão menos complexa, pois são muitos os temas e as áreas que Unasul pretende abordar. Com efeito, o artigo 3ํำ do TC dispõe de objetivos específicos, que vão desde o desenvolvimento social e humano, o desenvolvimento da infraestrutura, a cooperação em matéria de migração, o desenvolvimento científico e tecnológico, a promoção da diversidade cultural, o combate ao terrorismo e ao narcotráfico, entre outros (UNASUL, 2008).

Esse grande rol, ambicioso por si só, pode ser alvo de críticas exatamente por sua abrangência. Elsa Llanderrosas, por exemplo, embora veja com otimismo a Unasul, acredita que a abrangência de objetivos pode contribuir para dispersar a iniciativa, além do que, na sua opinião, as instituições criadas no âmbito da organização, sem qualquer nível de supranacionalidade, não seriam hábeis para cumprir esse programa (LLENDERROZAS 2012, p. 161). Por outro lado, há a visão otimista que põe em relevo o fato de os muitos temas tratados nos artigos $2^{\circ}$ e $3^{\circ}$ do TC expressarem um novo projeto para a integração, mais profundo do que até então se havia intentado. Maria Angela Cano Linares, por exemplo, afirma que o artigo 3 "implica un nuevo intento de plasmar el sueño del federalismo sudamericano" (LINARES,2010, p. 16). Paulo Bonavides, por sua vez, também acredita em uma solução "federal". No capítulo que escreveu para um dos poucos livros publicados no Brasil sobre a Unasul, defendeu a existência de uma "plataforma de unidade cultural" que serviria de base para institucionalizar a união dos estados sul-americanos na forma federal e também - e aqui, a Unasul se afasta dessa ideia - supranacional (BONAVIDES, 2011, p. 15-41).

O artigo $1^{\circ}$ do TC afirma a Unasul como uma entidade dotada de personalidade jurídica internacional. Nesse sentido, é uma evolução em relação às Reuniões de Presidentes da América do Sul e à CSN, que funcionavam como fóruns intergovernamentais despersonalizados. A necessidade de constituir uma verdadeira organização internacional para dar melhor seguimento ao processo iniciado em 2000 era consenso. O ponto que gerou discussões foi a natureza supranacional ou intergovernamental dessa organização. Houve uma proposta, minoritária e derrotada já no interior da Comissão de Altos Funcionários, que pretendia dar um caráter supranacional à Unasul, alegando que sem isso todos os objetivos, muito abrangentes, seriam apenas intenções sem a força cogente necessária para se efetivarem na realidade. Defendendo essa integração mais intensa atuou o ex-presidente equatoriano Rodrigo Borja Cevallos. Prestigiado a ponto de ser o primeiro a assumir Secretaria Geral da Unasul, Cevallos renunciou em maio de 2008 por discordar da adoção de uma integração de tipo intergovernamental. Sua proposta para o art. $2^{\circ}$ do TC foi rejeitada, mas vale a pena citá-la para ilustrar esse ponto de vista:

Artigo 2ํㅡ La autoridad y competencias de Unasur están dadas por la voluntad soberana de los Estados Miembros que, a cambio de la ventaja económica, política y geopolítica que la supeditación a un orden comunitario les puede oferecer, acuerden autolimitar algunas de sus potestades soberanas y formar la Unión con órganos comunitarios de decisión y acción multilaterales. (apud: SÓLON , 2008, p. 14.) 
Em lugar dessa proposta de uma Unasul dotada de supranacionalidade foi aprovada uma Unasul intergovernamental. O artigo 12 do TC trata desse tema e dispõe que "os atos normativos emanados dos órgãos da UNASUL serão obrigatórios para os Estados-membros uma vez que tenham sido incorporados no ordenamento jurídico de cada um deles, de acordo com seus respectivos procedimentos internos". A cogência de uma norma da Unasul só tem aplicabilidade direta nos estados-membros se passar pelo processo de incorporação ao seu direito interno. Também houve discussão entre partidários da supranacionalidade e da intergovernabilidade quanto aos poderes do Secretário-Geral. Diego Cardona Cardona, colombiano que ocupou a Secretaria do Conselho Andino de Ministros de Relações Exteriores, informa que houve membros do Conselho de Altos Funcionários que defendiam uma Secretaria Geral forte, como um embrião da supranacionalidade que viria no futuro (CARDONA, 2008, p. 24). Contudo, prevaleceu a posição dos que defendiam uma Secretaria Geral como a do Mercosul, atuando sob expresso mandato dos estados (art. 10 do TC).

Os órgãos da Unasul estão dispostos no artigo 4ํำ do TC: Conselho de Chefas e Chefes de Estado e de Governo; Conselho de Ministras e Ministros de Relações Exteriores; Conselho de Delegadas e Delegados e Secretaria-Geral. Há também a Presidencia Pro Tempore, prevista no artigo $7^{\circ}$ do TC, e uma determinação para a instituição de um Parlamento por meio de Protocolo Adicional (artigo 17 e Artigo Transitório do TC).

O artigo $2^{\circ}$ do Regulamento Geral da Unasul (UNASUL, SD) acrescenta ainda os Conselhos Ministeriais Setoriais e as demais instâncias previstas no artigo $5^{\text {o }}$ do tratado para o desenvolvimento institucional da organização, como Grupos de Trabalho ou outras formas a serem criadas. Atualmente, existem doze conselhos ministeriais em funcionamento na Unasul. Organizado hierarquicamente, o organograma da Unasul é o seguinte: o órgão máximo da Unasul é o Conselho de Chefas e Chefes de Estado e de Governo (CCCEG), composto pelos governantes dos doze países-membros. Sua principal atribuição é estabelecer "as diretrizes políticas, os planos de ação, os programas e os projetos do processo de integração sul-americana e decidir as prioridades para sua implementação", conforme o artigo 6ำ do TC. Também é responsabilidade sua definir as diretrizes políticas da Unasul no tratamento com terceiros. Em outras palavras, o CCCEG é responsável pela elaboração e direção políticas do processo de integração. A aprovação da criação dos Conselhos Ministeriais Setoriais, do ingresso de novos membros e das emendas ao TC são também atribuições do CCCEG (artigos 6ํ, 20 e 25 do TC). Suas normas são as Decisões, que compõem o conjunto das fontes jurídicas da Unasul (artigo 11, 3 do TC). As Decisões, assim como qualquer norma adotada pela Unasul, só podem ser aprovadas mediante consenso (artigo 12 do TC). O CCCEG realiza anualmente reuniões ordinárias, podendo haver reuniões extraordinárias caso algum país as convoque, na dependência de aprovação pelos outros membros do Conselho.

A Presidência Pro Tempore, prevista no artigo $7^{\circ}$ do TC, é exercida em mandatos anuais por cada um dos estados-membros, respeitada a ordem alfabética para a alternância. É sua atribuição preparar, convocar e presidir as reuniões da Unasul, sendo que elas acontecem no território do país que estiver no exercício da Presidência Pro Tempore. Cabe a ela também a elaboração do programa anual de atividades da Unasul, definindo 
eventos, datas, locais, organização, dentre outros, em conjunto com a Secretaria Geral. Mediante aprovação prévia do CCCEG, a Presidência Pro Tempore representará a Unasul em instâncias internacionais, podendo firmar acordos em nome da organização.

O artigo $8^{\circ}$ do TC dispõe sobre o segundo órgão na escala hierárquica da Unasul, o Conselho de Ministras e Ministros das Relações Exteriores (CMMRE), dotado de diversas atribuições executivas, pois deve implementar as Decisões do CCCEG. Além disso, pode também apresentar propostas, emitindo Resoluções a serem aprovadas pelo Conselho Superior. É esse Conselho que dá seguimento às iniciativas elaboradas na instância de elaboração, promovendo a coordenação e concertação. Ele pode criar grupos de trabalho para atender às exigências do CCCEG e tem a atribuição de aprovar o programa anual de atividades, elaborado pela Presidência Pro Tempore em conjunto com a Secretaria Geral, e o orçamento anual da Unasul. Suas reuniões ordinárias são semestrais e pode haver reuniões extraordinárias mediante convocação da Presidência Pro Tempore e concordância de, ao menos, metade dos membros.

O terceiro órgão é o Conselho de Delegadas e Delegados (CDD), com atribuições reguladas pelo artigo 9ํㅜ do TC. Esse Conselho é composto por um representante de cada estado, especialmente designado. É a incorporação aos órgãos da Unasul da Comissão de Altos Funcionários que existiu sob a CSN. Sua função é assessorar o CMMRE, preparando suas reuniões, mas, mais que assessorar, pode elaborar propostas de Decisões, Resoluções e Regulamentos, devendo apresentá-las ao CMMRE que, no caso de aprovação, as levará ao CCCEG. É sua também a complexa tarefa de compatibilizar a Unasul com as demais organizações de integração regional e sub-regional, como o Mercosul e a CAN, um tema extremamente importante pois a Unasul pretende ser o instrumento de convergência entre esses dois blocos já existentes. O CDD também possui tarefas executivas como levar adiante os Grupos de Trabalho criados pelo CMMRE, promover espaços para consolidar a participação cidadã no processo de integração e analisar e propor ao Conselho imediatamente superior o projeto de orçamento anual da organização. $\mathrm{O}$ artigo 9ํㅗㄱo TC determina que as reuniões do CDD têm periodicidade "preferencialmente bimestral".

O quarto e último órgão relacionado pelo artigo 4ํe é a Secretaria Geral, com sede em Quito, Equador, e um corpo de funcionários oriundos equitativamente de todos os Estados-membros. O Secretário Geral é designado pelo CCCEG a partir de nome proposto pelo CMMRE. Seu mandato é de dois anos, prorrogável uma vez. Conforme o artigo 10 do TC, as funções da Secretaria são elaborar um documento de memória anual e os informes da organização, ser depositária dos acordos e responsável pela sua publicação, elaborar o projeto de orçamento anual para submissão ao CDD e, por fim, articular-se com outras organizações de integração latino-americanas para desenvolver as atividades determinadas pelos órgãos da Unasul. O Secretário Geral tem a atribuição de secretariar as reuniões dos órgãos da Unasul, com direito à voz.

Há ainda a previsão de se constituir, no futuro, um Parlamento da Unasul. Ele não consta entre os órgãos do artigo $4^{\circ}$, mas o artigo 17 determina que seja aprovado um Protocolo Adicional criando esse Parlamento e suas atribuições, já definindo que sua sede será a cidade de Cochabamba, na Bolívia. O Artigo Transitório, por sua vez, determina a 
Criação de uma Comissão Especial coordenada pelo CDD e composta por representantes dos parlamentos nacionais dos países-membros, além dos parlamentos regionais e sub-regionais já existentes, para elaborar o projeto de Protocolo Adicional. Em junho de 2010, reuniram-se no Equador os presidentes dos Parlamentos nacionais para discutir a proposta elaborada por aquela comissão. Decidiu-se que o texto final deveria ser discutido em cada um dos parlamentos, a fim se obter uma posição consensual. Por conta disso, ainda não existe um projeto de Protocolo Adicional, embora os debates estejam em curso.

Analisando o organograma da organização, Raquel Coelho Lenz César afirma que "as bases político-institucionais da CAN constituem-se em estrutura funcional da Unasul" (LENS CESAR, 2011, p. 23). Por sua vez, a estrutura da CAN é inspirada na União Europeia.

A nosso ver, concordando com Diego Cardona Cardona (CARDONA, 2010, p. 15), a estrutura institucional da Unasul, até por conta de sua pretensão de ser uma organização para "integração da integração", nas palavras de Maria Angela Cano Linares (2010, p. 15), mescla os órgãos do Mecanismo Permanente de Consulta e Concertação Política, também conhecido como Grupo do Rio, com organizações próprias da integração regional. O Grupo do Rio surgiu 1986 como um espaço de concertação política para os países latino-americanos, tendo evoluído para a formação da Comunidade de Estados Latino-americanos e Caribenhos (CELAC), fundada em fevereiro de 2010. Sem uma estrutura organizacional permanente o Grupo do Rio e, agora, a CELAC tem como órgão principal as reuniões de chefas e chefes de estado e governo da América Latina ${ }^{(2)}$. Esse sistema, experimentado há mais de 20 anos pela região, legou à Unasul seus órgãos principais: o CCCEG, o CMMRE e o CDD. Por sua vez, os organismos próprios da integração também foram incorporados, como a Secretaria Geral, os grupos setoriais (Conselhos Ministeriais da Unasul) e o Parlamento, ainda em fase de discussão. Assim, a nosso ver, as instituições da Unasul são o resultado do aproveitamento e adaptação das instituições dos grupos regionais de cooperação política e das organizações de integração econômica. Outra herança própria da experiência de organizações de integração regional seria um sistema de solução de controvérsias. Contudo, o artigo 21 do TC, que trata desse tema, não oferece um verdadeiro sistema, como veremos adiante.

Podem ainda ser criadas novas instituições, a serem definidas conforme a conveniência. $\mathrm{O}$ artigo $5^{\circ}$ do TC trata do desenvolvimento da institucionalidade e prevê a criação de Grupos de Trabalho e Conselhos Ministeriais, deixando aberta a possibilidade de outras formas ainda não tratadas serem incorporadas à Unasul (como um Tribunal, como reclamado por José Sebastião Fagundes Cunha) (CUNHA, 2011). O artigo 13 detalha melhor a questão e abre também a possibilidade de inclusão de novas políticas.

Como já dissemos, todas as decisões são tomadas por consenso. O quórum mínimo para se adotar uma medida é de $3 / 4$ dos membros, em qualquer dos três Conselhos.

(2) Informações disponíveis em: <http://www.itamaraty.gov.br/temas/america-do-sul-e-integracao-regional/celac > Acesso em: 17.05.2013. 
No caso de ausência de membros e havendo quórum, a decisão pode ser tomada com a condição de consulta posterior feita pelo Secretário Geral aos estados ausentes, que terão 30 dias para manifestar-se contados após o recebimento da comunicação. Os ausentes também devem concordar para que se efetive a decisão. Pablo Sólon diz que essa fórmula pode trazer inconvenientes, mas sem ela o TC não teria sido aprovado (SOLÓN, 2008, p. 13).

O artigo 13, reforçando o caráter intergovernamental da organização e o primado da soberania nacional dos países-membros, dispõe que nenhum Estado é obrigado a aplicar total ou parcialmente uma política adotada pela Unasul ou mesmo participar de uma instituição nova que venha a ser criada. Uma das balizas do modelo de integração proposto pela Unasul é a adoção de critérios flexíveis e graduais de implementação de qualquer política ou instância como decorrência, acreditamos nós, do reconhecimento das assimetrias entre os países sul-americanos. Metas iguais para Estados desiguais não atenderiam ao desafio de convergir uma região com tantas disparidades e a partir de blocos e países com políticas comerciais e econômicas diversas. Por isso, a Unasul se ampara no respeito à dinâmica interna de cada membro. O problema é que se, por um lado, isso permitiu que se chegasse ao acordo que fundou a organização, por outro, enfraquece a Unasul na consecução de seus ambiciosos objetivos. Até por conta dessa natureza um tanto paradoxal, o TC achou necessário afirmar, em seu artigo 14, segunda parte, o princípio do diálogo político como orientador da Unasul: "os estados membros reforçarão a prática de construção de consensos no que se refere aos temas centrais da agenda internacional e promoverão iniciativas que afirmem a identidade da região como um fator dinâmico nas relações internacionais."

Também reflexo dessa "fraqueza" institucional que paradoxalmente é a força da Unasul, pois possibilitou sua existência, não existe um sistema de solução de controvérsias institucionalizado. No caso de desavenças entre os membros quanto à aplicação ou interpretação das disposições do tratado, o artigo 21 determina a realização de negociações diretas (ou seja, política e não direito). Caso não se chegue a um acordo, será acionado o CDD com atribuição de formular recomendações. Caso ainda assim não se chegue a um entendimento, será acionado o CMMRE, que considerará o caso. O artigo não afirma se a decisão do Conselho é cogente ou não, havendo essa lacuna. Interpretando-o à luz das disposições que vimos acima, dificilmente a Unasul terá poder para impor sua decisão no caso de um impasse como esse. Como até o momento não ocorreu nenhuma situação semelhante, não temos um precedente para afirmar como se resolve, afinal, uma controvérsia entre os membros.

O TC prevê também uma ampla participação da sociedade civil na Unasul, até por uma exigência lógica de seus objetivos, como a constituição de uma identidade sul-americana, o intercâmbio cultural ou, ainda, a perspectiva de uma anunciada integração dos povos e não apenas dos mercados. Mas, para além disso, esse mandamento, expresso no Preâmbulo e nos artigos $2^{\circ}$ (objetivo geral), 3ํㅡㄴ (objetivos específicos) e 18 do TC, exprime uma orientação para a democratização das instâncias que decidem os rumos da integração. Porém, também aqui não existe o espaço institucional que dê vazão a essa orientação. O artigo 18 dispõe que os estados e os órgãos da Unasul têm 
o dever de criar "espaços inovadores" que possibilitem a atuação da sociedade civil no processo de integração, mas não os estabelece já no âmbito do TC. Dado que a Unasul concebe o que podemos chamar de uma institucionalidade aberta, como vimos antes, o fato de o artigo 18 não se limitar a um mandamento pró-participação da sociedade civil não é necessariamente negativo, pois é possível que o conselho específico para essa área formule a instituição adequada para esse objetivo. Contudo, a garantia de efetivação de espaços institucionais para que a cidadania, e não apenas os técnicos dos governos, se expresse ainda é uma promessa para o futuro. Andrés Serbin (2012, p. 76-77), professor na Universidade Central da Venezuela, alerta que a tendência de centrar a tomada de decisões exclusivamente nos chefes do Poder Executivo contrasta com a exigência das sociedades sul-americanas por mais democracia. Na opinião desse analista, o próprio caráter intergovernamental contribuiria para impedir a emergência de um projeto de integração vindo desde os povos. Nessa mesma linha, Gilberto M. A. Rodrigues e Thiago Rodrigues (2011) afirmam que no TC "no hay ningún mecanismo efectivo que garantice juridicamente que se respetarán el espacio y las demandas de la sociedade civil frente a los órganos de Unasul". Essa crítica não quer dizer que não foram dados passos no sentido de cumprir a diretriz do artigo 18. O CCCEG aprovou, em reunião realizada em Lima, Peru, em novembro de 2012, a Decisão 7/2012 (UNASUL, 2012) criando um Fórum de Participação Cidadã da Unasul, com reuniões anuais e capacidade para apresentar propostas ao CCCEG. As diretrizes deste Fórum foram elaboradas pelo CDD, como aliás já dispunha o artigo 15 do Regulamento Geral da Unasul, e aprovadas em setembro de 2013. A Decisão 7/2012 ainda determina que a Secretaria Geral deve atuar no sentido de levar cada Conselho setorial a estabelecer canais eletrônicos de comunicação e divulgação de informações, além de promover eventos que possibilitem a participação dos diversos atores da sociedade civil. A perspectiva é de que, no início de 2014, seja realizada a primeira reunião do Fórum de Participação Cidadã, em Cochabamba, na Bolívia.

Outro tema objeto do tratado é a relação entre os conceitos de América do Sul e América Latina. Ao procurar constituir um espaço integrado sul-americano, a Unasul propõe uma nova identidade que se pretende complementar e não substitutiva da identidade latino-americana. É forçoso reconhecer, antes de mais nada, que a própria realidade política do continente leva a uma opção pela América do Sul quando se pensa uma organização de integração abrangente, dado que o México, principal país latino-americano fora da América do Sul, integra a North America Free Trade Area (NAFTA). Se é complexo pensar uma área de livre-comércio com Mercosul, CAN, Chile, Suriname e Guiana, pensá-la incluindo o México é hoje uma impossibilidade. Mas a força da ideia de América Latina não permitiu que a Unasul rompesse com ela. O TC trata disso no artigo 19, dispondo sobre a incorporação de outros países. Diz esse artigo que são admitidos novos membros desde que sejam estados da América Latina e do Caribe. O artigo 20 define um processo para essa adesão: elas só podem se iniciar após cinco anos da entrada em vigor do TC (ou seja, a partir de 11/03/2016) e os candidatos devem ter passado quatro anos com o status de estados observadores. Assim, embora se afirme como um espaço sul-americano, a Unasul poderá no futuro incorporar novos membros caminhando no rumo de uma organização mais latina do que sul-americana. 
Celso Amorim, ministro de Relações Exteriores do Brasil durante os governos de Luís Inácio Lula da Silva (2003-2010), cuja gestão negociou e constituiu a Unasul, explica essa opção pela América do Sul como uma escolha geopolítica. Ele afirma que o Brasil optou por enfatizar esse conceito em detrimento do de América Latina e mesmo do de Cone Sul por duas razões: uma é geográfica — "você olha o Brasil e está olhando a América do Sul, mas não necessariamente a América Latina" (AMORIM, 2011, p. 376) - e a outra é a necessidade de garantir um entorno pacífico para o Brasil, maior país da América do Sul. Não exatamente concordando com esse ponto de vista, Miguel Ángel Barrios concorda com o argumento de que a própria geografia do Brasil o volta para a América do Sul:

"Para un brasileño, comprender sus fronteras es pensar el conjunto de América del Sur. Cuando comenzó a hacerse necesario pensar el desarrollo brasileño en su totalidad, pensar a Brasil requería pensar a su vecindad. Y la vecindad concreta de Brasil es toda América del Sur, el gran cuerpo de América Latina. Esto es más difícil para cada país hispanoamericano de América del Sur, pues ninguno limita con el conjunto de América del Sur como Brasil." (BARRIOS, 2011, p. 92.)

Há também quem entenda a Unasul e a afirmação de um conceito diferente do de América Latina como uma resposta da diplomacia brasileira à influência que a Venezuela sob os governos de Hugo Rafael Chávez Frías (1999-2013) exerceu na região. Nesse sentido, a Unasul seria uma iniciativa para consolidar a liderança brasileira na região e atender às pretensões do Brasil de inserir-se cada vez mais como ator global. A cientista política Miriam Gomes Saraiva, por exemplo, acredita que a Unasul "es un mecanismo que hace hincapié en la dimensión política de la política brasileña para la región" (SARAIVA, 2012, p. 98). Outro pesquisador, José Antonio Sanahuja, pensa que a ideia de América do Sul responde à busca do Brasil pela liderança da região já que afasta de pronto a influência do México, diretamente afetado pelos Estados Unidos. A Unasul daria ao Brasil uma plataforma para sua liderança nos temas políticos e de defesa na região, além de reforçá-lo como ator global. Além disso, abriria mais mercados para a indústria brasileira e daria um acesso mais fácil aos portos do Pacífico. Essa organização teria logrado conciliar, dentro do Brasil, os interesses econômicos do setor privado, o projeto geopolítico das Forças Armadas e do setor da diplomacia elevado ao poder por Lula e também o pensamento contra-hegemônico de setores do Partido dos Trabalhadores (PT) e grupos políticos próximos a ele (SANAHUJA, 2012, p. 36-37). Já para José Briceño Ruiz, em uma linha um pouco diferente, a Unasul, com suas metas sociais, é a síntese surgida do enfrentamento entre a posição brasileira e a defendida pelos países da ALBA, em especial a Venezuela (RUIZ, 2010, p. 103). De todo modo, o dispositivo do TC que trata da adesão de novos membros é um reconhecimento da força do latino-americanismo por uma inciativa que pretende firmar uma identidade sul-americana.

\section{CONSIDERAÇÕES FINAIS}

Como vimos, a Unasul é considerada por muitos uma iniciativa que renova as instituições e o debate sobre integração regional. Essa novidade estaria exatamente no fato 
de os objetivos que a Unasul pretende alcançar serem mais amplos que os tradicionais objetivos comerciais e econômicos. A Unasul se apresenta também como uma organização voltada à integração e melhoria da qualidade de vida dos seus povos, além de um fórum de concertação política que leve a região a se apresentar como um todo unido ante o resto do mundo. Contudo, vimos também que as instituições criadas no âmbito da organização, em que pese o apelo ao ideal de unidade, podem ser acusadas de inaptas a tais objetivos, posto que não se aceita nenhum grau de supranacionalidade e sequer se formou um sistema de solução de controvérsias. Em contrapartida, a Unasul é constituída a partir do que chamamos de institucionalidade aberta, pois novos órgãos podem ser criados no futuro sob nova natureza, a depender do consenso de seus membros. De todo modo, existem questões e críticas que devem ser enfrentadas.

Uma das mais importantes ressalvas formuladas é a que diz respeito ao papel que a Unasul deve representar em um cenário que já conta com experiências de integração que, embora tenham seus problemas, é necessário reconhecer que são as mais bem-sucedidas da história da região. Esse é o caso do Mercosul. Samuel Pinheiro Guimarães, quando renunciou ao cargo de Alto Representante Geral do Mercosul em junho de 2012, acentuou a importância daquela organização e, de certa forma, relativizou o papel a ser desempenhado pela Unasul:

A Unasul, apesar de sua importância política, não pode ser a pedra fundamental para a construção do bloco econômico da América do Sul. O Chile, a Colômbia e o Peru adotaram estratégias de inserção internacional que levaram à adoção de certas normas comerciais, de investimentos, de capital estrangeiro, de propriedade intelectual, etc., que dificultam e até impossibilitam a construção de políticas regionais de promoção do desenvolvimento (...) O bloco econômico da América do Sul terá de ser formado a partir da expansão gradual do Mercosul. (GUIMARÃES, 2012.)

Félix Peña reflete sobre essa questão e aponta os desafios colocados à institucionalização do espaço sul-americano. Para ele, trata-se de conseguir conciliar os vários espaços de inserção regional e global existentes e também de dar credibilidade aos âmbitos institucionais. Argumenta que ainda está por se descobrir se a Unasul conseguirá responder tais desafios, fazendo com que suas instituições se comuniquem efetivamente com a realidade da região e não seja apenas mais uma organização em uma história repleta delas. Nas palavras de Félix Peña (2009, p. 82), "a distância entre construções formais e fatos concretos costuma ser significativa em uma região onde pareceria ser mais fácil criar instituições que utilizá-las em sua plenitude". Essa é uma questão central que a Unasul deve enfrentar. Como conseguir isso sem procurar ocupar um espaço já preenchido pelo Mercosul, que vem progressivamente se ampliando tanto comercial como politicamente e que inclusive já está consolidando uma identidade? Para Peña, o melhor cenário possível é aquele no qual as duas organizações se complementam, com o Mercosul cumprindo o papel de estrutura da Unasul. Mas o pior cenário - e esse é seu alerta - é aquele em que a Unasul ocupa o espaço, assumindo para si os objetivos políticos sem conseguir lograr avanços, deixando o Mercosul estagnado.

A nosso ver, a Unasul foi formulada para criar um espaço institucional regional que não é possível nos marcos do Mercosul, exatamente por conta da adesão de países que, 
como o Chile, adotam uma estratégia diferente da união aduaneira proposta. O papel principal da Unasul, embora fale em constituir no futuro uma aproximação entre CAN, Mercosul e demais países da região, é de convergência política. Além disso, o fato de afirmar valores como uma identidade própria e autonomia resgata um compromisso com a soberania de um continente rico em recursos naturais cada vez mais disputados no mundo. Evidentemente, só a vontade política dos países-membros e de seus povos dirá se a Unasul conseguirá, no futuro, vencer os desafios e contradições inerentes à natureza de sua iniciativa, constituindo-se na organização que seu TC pretende que ela seja.

\section{BIBLIOGRAFIA}

\subsection{FONTES BIBLIOGRÁFICAS}

AMORIM, Celso. Conversas com Jovens Diplomatas. São Paulo: Benvirá, 2011.

BARRIOS, Miguel Ángel. Consejo Suramericano de Defensa: desafios geopolíticos y perspectivas continentales. Buenos Aires: Biblos, 2011.

BONAVIDES, Paulo. Solução Federalista para o Problema da Unidade Latino-Americana. In: CADEMARTORI, D. M. L. de; MORAES, G. de O; CESAR, R. C. L; CADEMARTORI, S. U. de. A Construção Jurídica da Unasul. Florianópolis: FUNJAB e Editora UFSC, 2011. p. 15-41.

CARDONA, Diego Cardona. "El ABC de Unasur: doce preguntas y respuestas". Revista de la Integración Suramericana, Lima, Secretaria Geral da Comunidade Andina, p. 19-30, julho de 2008, n. 2. CELLI JUNIOR, Umberto. Teoria Geral da Integração: em busca de um modelo alternativo. In: MERCADANTE, A. de A.; CELLI JUNIOR, U.; ARAÚJO, L. R. de (org). Blocos Econômicos e Integração na América Latina, África e Ásia. Curitiba: Juruá, 2006.

CUNHA, José Sebastião Fagundes. Um Tribunal para a Unasul. Curitiba, 2011.

LENS CESAR, R. C. A Unasul e o Processo de Integração Latino-Americano. In: CADEMARTORI, D. M. L. de; MORAES, G. de O; CESAR, R. C. L; CADEMARTORI, S. U. de. A Construção Jurídica da Unasul. Florianópolis: FUNJAB e Editora UFSC, 2011. p. 15-41.

LLENDERROZAS, Elsa. Diálogo y Concertación Política en América Latina: Los Alcances de las Propuestas Regionales. In: SERBIN, Andrés; MARTÍNEZ, Laneydi; RAMANZINIJR., Haroldo (coord.). El Regionalismo "Post-Liberal" en América Latina y el Caribe: Nuevos Actores, Nuevos Temas, Nuevos Desafíos. Buenos Aires: CRIES, 2012.

LINARES, Maria Angela Cano. La Unión de Naciones Suramericanas: un ambicioso e inovador proceso de construcción de integración regional. Revista Eletrónica Iberoamericana — publicação do Centro de Estudos de Iberoamérica, vol. 4, n. 1, 2010, p. 11. Disponível em: <http://www.urjc. es/ceib/investigacion/publicaciones/REIB_04_10_Angelines.pdf> Acesso em: 03.05.2013.

NEGRO, Sandra Cecilia. Caracterización y classificación de los esquemas de integración regional. In: NEGRO, Sandra Cecilia (dir.). Derecho de la Integración — Manual. Montevideo/Buenos Aires: Editorial IB de F, SD.

PEÑA, Félix. La Integración del espacio sudamericano - ¿la Unasur y el Mercosur puden complementarse? In: Revista Nueva Sociedad, n. 219, p. 46-58, janeiro/fevereiro de 2009.

RIGGIROZZI, Pía. Re-territorializando consensos: hacia un regionalismo post-hegemónico en América Latina. In: SERBIN, Andrés; MARTÍNEZ, Laneydi; RAMANZINI JR., Haroldo (coord.). El Regionalismo "Post-Liberal" en América Latina y el Caribe: Nuevos Actores, Nuevos Temas, Nuevos Desafíos. Buenos Aires: CRIES, 2012. 
RODRIGUES, Gilberto M. A.; RODRIGUES, Thiago. La Unión de Naciones Suramericanas y los Nuevos Temas de la Agenda Regional de Paz y Seguridad: roles y mecanismos de participación de la sociedade civil. In: SERBIN, Andrés (coord.). De la ONU al ALBA: prevención de conflitos y espacios de participación ciudadana. Barcelona: CRIES e Icaria Editorial, 2011.

RUIZ, José Briceño. La Unasur: ¿Continuum o un nuevo inicio del regionalismo sudamericano? In: ALFONSO, L. M.; RAMANZINIJR., H.; VAZQUES, M. (coord.). Anuário de la Integración Regional de América Latina y el Gran Caribe. 2010. Disponível em: <www.cries.org/wp-content/uploads/2010/09/ completo.pdf> Acesso em: 06.04.2013.

SANAHUJA, José Antonio. Regionalismo Post-Liberal y Multilateralismo en Sudamérica: El Caso de la Unasur. In: SERBIN, Andrés; MARTÍNEZ, Laneydi; RAMANZINI JR., Haroldo (coord.). El Regionalismo "Post-Liberal" en América Latina y el Caribe: Nuevos Actores, Nuevos Temas, Nuevos Desafíos. Buenos Aires: CRIES, 2012.

SARAIVA, Miriam Gomes. Procesos de Integración de América del Sur y el Papel de Brasil: los casos del Mercosur y la Unasur. Revista CIDOB d'afers internationals, Barcelona, n. 97-98, p. 87-100, abril de 2012.

SERBIN, Andrés. Déficit Democrático y Participación Ciudadana en el Marco del Regionalismo Post-Liberal. In: SERBIN, Andrés; MARTÍNEZ, Laneydi; RAMANZINI JR., Haroldo (coord.). El Regionalismo "Post-Liberal" en América Latina y el Caribe: Nuevos Actores, Nuevos Temas, Nuevos Desafíos. Buenos Aires: CRIES, 2012, p. 73-127.

SÓLON, Pablo. Reflexiones a mano alzada sobre el tratado de Unasur. Revista de la Integración Suramericana, Lima, n. 02, p. 12-18, julho de 2008.

TORRES, César Augusto Bermúdez. Mercosur y Unasur: una mirada a la integración regional a comienzos del siglo XXI. Revista Análisis Político, Bogotá, n. 72, p. 115-131, maio-agosto de 2011.

\subsection{FONTES DOCUMENTAIS}

GUIMARÃES, Samuel Pinheiro. Relatório ao Conselho de Ministros, Montevidéu, junho de 2012. Disponível em: <http://www2.camara.leg.br/atividade-legislativa/comissoes/comissoes-mistas/ cpcms/publicacoeseeventos/relatorio-ao-conselho-de-ministros> Acesso em: 14.05.2013.

UNASUL. Tratado Constitutivo da Unasul. Brasília, 23 de maio de 2008. Disponível em: <http://www. unasursg.org/uploads/cb/f2/cbf2f9520ad902831b19a51f5b886959/Tratado-Constitutivo-version-portugues.pdf> Acesso em: 15.05.2013.

UNASUL. Regulamento Geral da Unasul. Quito, SD. Disponível em: <http://www.unasursg.org/inicio/ documentos/fuentes-juridicas/reglamento-general> Acesso em: 03.04.2013.

UNASUL. Unasur/cjeg/decisión/nำ7/2012. Quito, 29 de novembro de 2012. Disponível em: <http:// www.unasursg.org/uploads/ec/6d/ec6d2361a78211e8599442972eb20548/Decision-7-Foro-particpacion-ciudadana-Lima-30-noviembre-2012.pdf> Acesso em: 29.05.2013. 